\title{
Mössbauer effect studies and X-ray diffraction analysis of cobalt ferrite prepared in powder form by thermal decomposition method
}

\author{
M D JOSEPH SEBASTIAN, B RUDRASWAMY, M C RADHAKRISHNA and RAMANI* \\ Department of Physics, Bangalore University, Jnanabharathi, Bangalore 560 056, India
}

MS received 15 April 2002

\begin{abstract}
Cobalt ferrite $\left(\mathrm{Co}_{x} \mathrm{Fe}_{3-x} \mathrm{O}_{4}\right)$ is prepared in powder form by thermal decomposition of iron and cobalt salts and is analysed by X-ray diffraction and Mössbauer spectroscopic techniques. The variation of Mössbauer parameters, lattice parameters and crystallite size of the products formed with variation in the composition of $\mathrm{Fe}$ and $\mathrm{Co}$ ratios are studied. The studies confirm the formation of nano-size cobalt ferrite particles with defect structure and it is found to be maximum for the $\mathrm{Fe}: \mathrm{Co}=60: 40$ ratio of the initial precursor oxides.
\end{abstract}

Keywords. Cobalt ferrite; thermal decomposition; Mössbauer effect; X-ray diffraction.

\section{Introduction}

The variation of different physical properties with method of preparation (Vanderberghe et al 1980; Souad et al 2001) has made ferrite a most demanding and technologically important material (Martha 2000). Special interest on cobalt ferrite is due to their typical changes in magnetic (Warren et al 1999) and electrical properties with changes in the concentration of divalent metal ions (Kwang et al 2000) or by the substitution of the divalent ions by other metallic ions (Rajendran 2001; Abdeen et al 2002).

Fine powders of nano-sized inverse spinel type cobalt ferrite particles with defect structure have been prepared by isothermal decomposition of homogeneous mixture of hydrated nitrates of iron and cobalt with varying $\mathrm{Fe}$ : Co ratio. This particular method reduced the duration of preparation by avoiding sintering for long periods.

The variation of Mössbauer parameters, viz. isomer shift ' $\delta$ ', quadrupole splitting ' $\Delta$ ' and hyperfine field ' $H_{\mathrm{f}}$ ' with the increase of cobalt concentration have been studied. The site occupancy ratio and the number of defects present have also been calculated using Mössbauer spectra. By making use of X-ray diffraction (XRD) patterns, the lattice parameter and crystallite size of the cobalt ferrite particles are calculated and studied with the variation of $\mathrm{Fe}$ : Co ratio.

\section{Experimental}

Mixed oxides (solid solutions) of $\mathrm{Fe}: \mathrm{Co}=95: 5$ to $\mathrm{Fe}: \mathrm{Co}=5: 95$ in steps of 5 at. $\%$ of Co were prepared by

\footnotetext{
*Author for correspondence
}

thermal decomposition of the mixture of respective nitrates in the required stoichiometric ratios at $400^{\circ} \mathrm{C}$ in air for $4 \mathrm{~h}$ using crucible-type furnace (Thipperudraiah 2001).The criterion in choosing $4 \mathrm{~h}$ of heating at $400^{\circ} \mathrm{C}$ in preparing mixed $\mathrm{Fe}$ : Co oxides was based on the dynamic thermogravimetric studies on iron and cobalt nitrates (Drakshayani 1987). These homogeneously mixed oxides of iron and cobalt were further heated at $950^{\circ} \mathrm{C}$ (Randhawa 2000) in air for $4 \mathrm{~h}$ inside a muffle furnace and then cooled to room temperature. Different oxide phases of iron and cobalt have been identified, as shown in table 1, and characterized by X-ray diffraction analysis using $\mathrm{Cr}-\mathrm{K}_{\alpha}$ radiation.

Table 1. Phases identified by XRD.

\begin{tabular}{|c|c|c|c|}
\hline \multirow[b]{2}{*}{ Sample ratio } & \multicolumn{3}{|c|}{ Identified phases } \\
\hline & $\alpha-\mathrm{Fe}_{2} \mathrm{O}_{3}$ & $(\mathrm{CoFe})_{3} \mathrm{O}_{4}$ & $\mathrm{Co}_{3} \mathrm{O}_{4}$ \\
\hline $100: 0$ & $\sqrt{ }$ & $\mathrm{x}$ & $\mathrm{x}$ \\
\hline $95: 5$ & $\sqrt{ }$ & $\mathrm{x}$ & $\mathrm{x}$ \\
\hline $90: 10$ & $\sqrt{ }$ & $\sqrt{ }$ & $\mathrm{x}$ \\
\hline $80: 20$ & $\sqrt{ }$ & $\sqrt{ }$ & $\mathrm{x}$ \\
\hline $75: 25$ & $\sqrt{ }$ & $\sqrt{ }$ & $\mathrm{x}$ \\
\hline $70: 30$ & $\sqrt{ }$ & $\sqrt{ }$ & $\mathrm{x}$ \\
\hline $60: 40$ & $\sqrt{ }$ & $\sqrt{ }$ & $\mathrm{x}$ \\
\hline $50: 50$ & $\sqrt{ }$ & $\sqrt{ }$ & $\sqrt{ }$ \\
\hline $40: 60$ & $\sqrt{ }$ & $\sqrt{ }$ & $\sqrt{ }$ \\
\hline $35: 65$ & $\sqrt{ }$ & $\sqrt{ }$ & $\sqrt{ }$ \\
\hline $25: 75$ & $\sqrt{ }$ & $\sqrt{ }$ & $\sqrt{ }$ \\
\hline $20: 80$ & $\sqrt{ }$ & $\sqrt{ }$ & $\sqrt{ }$ \\
\hline $10: 90$ & $\sqrt{ }$ & $\mathrm{x}$ & $\sqrt{ }$ \\
\hline $5: 95$ & $\mathrm{x}$ & $\mathrm{x}$ & $\sqrt{ }$ \\
\hline $1: 99$ & $\mathrm{x}$ & $\mathrm{x}$ & $\sqrt{ }$ \\
\hline $0: 100$ & $\mathrm{x}$ & $\mathrm{x}$ & $\sqrt{ }$ \\
\hline
\end{tabular}

$\sqrt{ }$, for presence of the phase; $x$, for absence of the phase. 
The Mössbauer spectrum of each sample with different $\mathrm{Fe}$ : Co ratios has been recorded with a ${ }^{57} \mathrm{Co}(\mathrm{Rh})$ source in constant acceleration mode to identify and confirm (see table 2) the magnetic phase of the spinel cobalt ferrite. The recorded Mössbauer data were computer fitted by the versatile program NMOSFIT. The fitted Mössbauer spectra and X-ray diffractograms of each sample are displayed in figures 1 and 2, respectively. The calculated values of Mössbauer parameters are tabulated in table 3 and that of lattice parameters, crystallite size, etc from XRD are shown in table 4.

\section{Results and discussion}

Both the Mössbauer and XRD patterns of initial samples rich in iron content gave only $\alpha-\mathrm{Fe}_{2} \mathrm{O}_{3}$ phase. Similarly, the final samples rich in cobalt content gave only the $\mathrm{Co}_{3} \mathrm{O}_{4}$ phase, i.e. only the oxide phase of the major con- tent of the sample present in the mixed oxides (Note that $\mathrm{Co}_{3} \mathrm{O}_{4}$ phase cannot be detected by Mössbauer technique). The intermediate samples with $\mathrm{Fe}: \mathrm{Co}$ ratio varying from $\mathrm{Fe}: \mathrm{Co}=80: 20$ to $\mathrm{Fe}: \mathrm{Co}=20: 80$ have indicated cobalt ferrite phase also in addition to other oxide phases of iron and cobalt. Typical individual peaks were obtained for each phase by XRD patterns. Mössbauer spectra of these intermediate samples indicate a combination of phases as could be ascertained from a considerable increase in the line width and some 'kinks' observed on each peak, i.e. each Mössbauer spectrum is a combination of two or three sextets. Using NMOSFIT program this could be resolved into the individual sextets of each phase. For the cobalt ferrite phase Mössbauer spectra gave two sets of sextets due to $\mathrm{Fe}^{3+}$ ions occupying tetrahedral (A) site and octahedral (B) site of the inverse spinel structure. Those kinks observed in Mössbauer spectra of the intermediate samples are a clear indication of this. The hyperfine fields calculated using

Table 2. Phases identified by Mössbauer spectra.

\begin{tabular}{|c|c|c|c|c|c|}
\hline \multirow[b]{3}{*}{ Sample ratio } & \multicolumn{5}{|c|}{ Identified phases } \\
\hline & \multirow[b]{2}{*}{$\alpha-\mathrm{Fe}_{2} \mathrm{O}_{3}$} & \multicolumn{3}{|c|}{$(\mathrm{CoFe})_{3} \mathrm{O}_{4}$} & \multirow[b]{2}{*}{$\mathrm{Co}_{3} \mathrm{O}$} \\
\hline & & A-site & Central & B-site & \\
\hline $100: 0$ & $\sqrt{ }$ & $\mathrm{x}$ & & $\mathrm{x}$ & $\mathrm{x}$ \\
\hline $95: 5$ & $\sqrt{ }$ & $\mathrm{x}$ & $\sqrt{ }$ & $\mathrm{x}$ & $\mathrm{x}$ \\
\hline $90: 10$ & $\sqrt{ }$ & $\sqrt{ }$ & $\mathrm{x}$ & $\sqrt{ }$ & $\mathrm{x}$ \\
\hline $80: 20$ & $\sqrt{ }$ & $\sqrt{ }$ & $\mathrm{x}$ & $\sqrt{ }$ & $\mathrm{x}$ \\
\hline $75: 25$ & $\sqrt{ }$ & $\sqrt{ }$ & $\mathrm{x}$ & $\sqrt{ }$ & $\mathrm{x}$ \\
\hline $70: 30$ & $\sqrt{ }$ & $\sqrt{ }$ & $\mathrm{x}$ & $\sqrt{ }$ & $\mathrm{x}$ \\
\hline $60: 40$ & $\mathrm{x}$ & $\sqrt{ }$ & $\mathrm{x}$ & $\sqrt{ }$ & $\mathrm{x}$ \\
\hline $50: 50$ & $\mathrm{x}$ & $\sqrt{ }$ & $\mathrm{x}$ & $\sqrt{ }$ & $\mathrm{x}$ \\
\hline $40: 60$ & $\mathrm{x}$ & $\sqrt{ }$ & $\mathrm{x}$ & $\sqrt{ }$ & $\mathrm{x}$ \\
\hline $35: 65$ & $\mathrm{x}$ & $\sqrt{ }$ & $\mathrm{x}$ & $\sqrt{ }$ & $\mathrm{x}$ \\
\hline $25: 75$ & $\mathrm{x}$ & $\sqrt{ }$ & $\sqrt{ }$ & $\sqrt{ }$ & $\mathrm{x}$ \\
\hline $20: 80$ & $\mathrm{x}$ & $\sqrt{ }$ & $\sqrt{ }$ & $\sqrt{ }$ & $\mathrm{x}$ \\
\hline $10: 90$ & $\mathrm{x}$ & $\mathrm{x}$ & $\sqrt{ }$ & $\mathrm{x}$ & $\mathrm{x}$ \\
\hline $5: 95$ & $\mathrm{x}$ & $\mathrm{x}$ & $\sqrt{ }$ & $\mathrm{x}$ & $\mathrm{x}$ \\
\hline $1: 99$ & $\mathrm{x}$ & $\mathrm{x}$ & $\sqrt{ }$ & $\mathrm{x}$ & $\mathrm{x}$ \\
\hline $0: 100$ & $\mathrm{x}$ & $\mathrm{x}$ & $\mathrm{x}$ & $\mathrm{x}$ & $\mathrm{x}$ \\
\hline
\end{tabular}

$\sqrt{ }$, for presence of the phase; $x$, for absence of the phase.

Table 3. Mössbauer parameters of $(\mathrm{CoFe})_{3} \mathrm{O}_{4}$ phase.

\begin{tabular}{|c|c|c|c|c|c|c|c|c|}
\hline \multirow[b]{2}{*}{ Sample ratio } & \multicolumn{2}{|c|}{$\begin{array}{l}\text { Isomer shift ' } \delta \text { ' } \\
( \pm 0.0547 \mathrm{~mm} / \mathrm{s})\end{array}$} & \multicolumn{2}{|c|}{$\begin{array}{c}\text { Quadrupole splitting } \\
\Delta( \pm 0.0547 \mathrm{~mm} / \mathrm{s})\end{array}$} & \multicolumn{2}{|c|}{$\begin{array}{l}\text { Hyperfine field, } H_{\mathrm{f}} \\
\quad( \pm 3 \mathrm{KOe})\end{array}$} & \multirow{2}{*}{$\begin{array}{l}\text { Site occupancy ratio } \\
S_{\mathrm{A}} / S_{\mathrm{B}}=\mathrm{V} \pm 0 \cdot 3\end{array}$} & \multirow{2}{*}{$\begin{array}{l}\text { No. of defects, } Z \\
\quad( \pm 0.03)\end{array}$} \\
\hline & A-site & B-site & A-site & B-site & A-site & B-site & & \\
\hline $80: 20$ & $0 \cdot 362$ & $0 \cdot 366$ & $0 \cdot 147$ & $0 \cdot 240$ & $503 \cdot 0$ & $483 \cdot 5$ & $2 \cdot 49$ & $0 \cdot 200$ \\
\hline $70: 30$ & $0 \cdot 419$ & $0 \cdot 442$ & $0 \cdot 208$ & $0 \cdot 346$ & $487 \cdot 0$ & $457 \cdot 9$ & $2 \cdot 60$ & $0 \cdot 204$ \\
\hline $60: 40$ & $0 \cdot 351$ & $0 \cdot 272$ & $0 \cdot 268$ & $0 \cdot 281$ & $501 \cdot 8$ & $475 \cdot 5$ & $0 \cdot 845$ & 0.069 \\
\hline $50: 50$ & $0 \cdot 351$ & $0 \cdot 386$ & $0 \cdot 186$ & $0 \cdot 278$ & 483.5 & $457 \cdot 2$ & 0.604 & $0 \cdot 024$ \\
\hline $40: 60$ & $0 \cdot 287$ & $0 \cdot 262$ & $0 \cdot 341$ & $0 \cdot 256$ & $463 \cdot 6$ & $443 \cdot 5$ & $1 \cdot 156$ & $0 \cdot 110$ \\
\hline $25: 75$ & $0 \cdot 296$ & $0 \cdot 270$ & $0 \cdot 225$ & $0 \cdot 159$ & $478 \cdot 9$ & $448 \cdot 2$ & $1 \cdot 143$ & $0 \cdot 110$ \\
\hline
\end{tabular}


the final parameter obtained on curve fitting confirmed that these sextets are formed due to the A and B sublattice sites. The calculated values of lattice parameter and the crystallite size by using XRD also coincide very well with their standard values. They are in agreement

Table 4. Lattice parameter and crystallite size of $(\mathrm{CoFe})_{3} \mathrm{O}_{4}$.

\begin{tabular}{lccc}
$\begin{array}{l}\text { Sample } \\
\text { ratio }\end{array}$ & $\begin{array}{c}\text { Crystallite } \\
\text { size } \pm 20(\AA)\end{array}$ & $\begin{array}{c}\text { Lattice parameter } \\
a(\AA)\end{array}$ & $\begin{array}{c}\text { Unit cell } \\
\text { volume, } V\left(\AA^{3}\right)\end{array}$ \\
\hline $80: 20$ & $424 \cdot 5$ & $7 \cdot 819$ & $477 \cdot 0$ \\
$70: 30$ & $545 \cdot 1$ & $7 \cdot 805$ & $475 \cdot 5$ \\
$60: 40$ & $548 \cdot 0$ & $7 \cdot 818$ & $477 \cdot 8$ \\
$50: 50$ & $350 \cdot 9$ & $7 \cdot 794$ & $473 \cdot 5$ \\
$40: 60$ & $351 \cdot 2$ & $7 \cdot 770$ & $469 \cdot 1$ \\
$25: 75$ & $139 \cdot 1$ & $7 \cdot 698$ & $456 \cdot 2$ \\
\hline
\end{tabular}

Channel Nos.
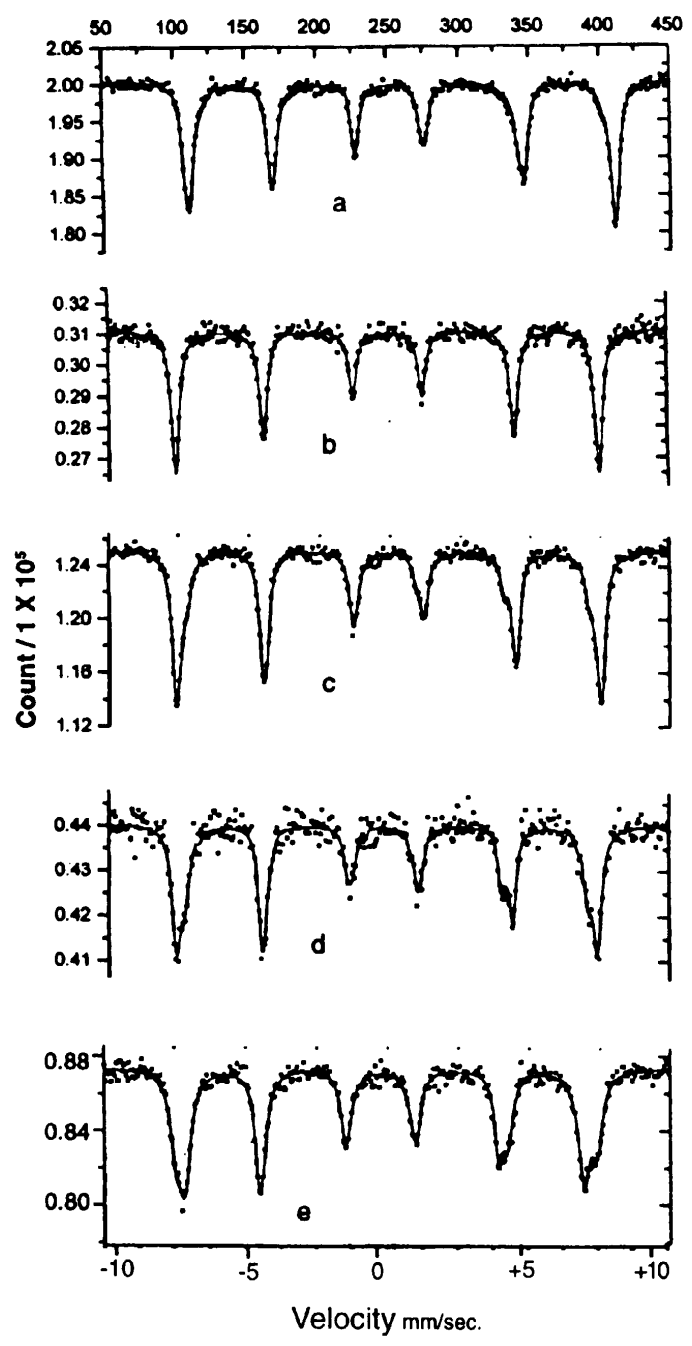

with the results obtained by Drakshayani (1994) on the effects of dopants on ferrite oxides.

Table 3 shows that the isomer shift ' $\delta$ ' for both A and B sites of cobalt ferrite phase has a constant value of $0.35 \mathrm{~mm} / \mathrm{s}$. The quadrupole splitting ' $\Delta$ ' also shows the values $0.27 \mathrm{~mm} / \mathrm{s}$ and $0.28 \mathrm{~mm} / \mathrm{s}$ for $A$ and $B$ sites, respectively. The hyperfine field, $H_{\mathrm{f}}$, due to both $\mathrm{A}$ and $\mathrm{B}$ sites of these ferrite phase shows a gradual decrease with increase of cobalt concentration and the field values of the sample $\mathrm{Fe}: \mathrm{Co}=60: 40$ coincides very well with the standard values. This is an indication that this proportion ( $\mathrm{Fe}: \mathrm{Co}=60: 40)$ is perhaps more appropriate ratio for ferrite formation. The slight variations are due to the presence of the defect structure.

The XRD measurements given in table 4 show that the lattice parameter almost had a constant value of $7 \cdot 8 \AA$ for
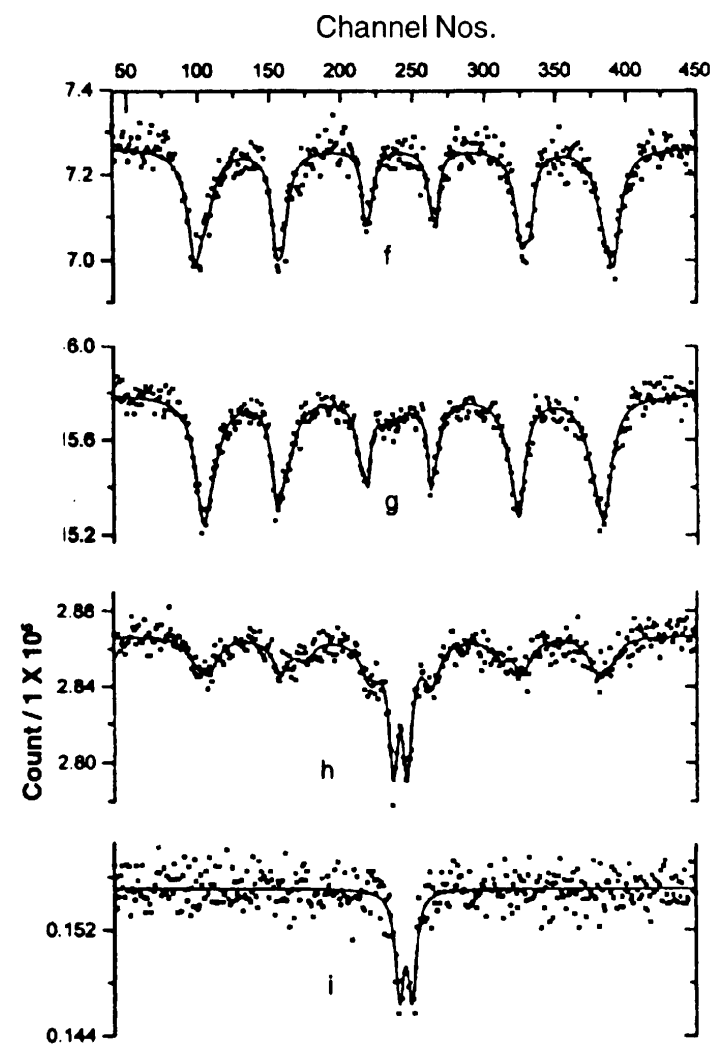

a) $\mathrm{Fe}: \mathrm{Co}=100: 0$, b) $\mathrm{Fe}: \mathrm{Co}=90: 10$, c) $\mathrm{Fe}: \mathrm{Co}=80: 20$, d) $\mathrm{Fe}: \mathrm{Co}=70: 30$, e) $\mathrm{Fe}: \mathrm{Co}=60: 40$,

f) $\mathrm{Fe}: \mathrm{Co}=50: 50$, g) $\mathrm{Fe}: \mathrm{Co}=40: 60$, h) $\mathrm{Fe}: \mathrm{Co}=25: 75$, i) $\mathrm{Fe}: \mathrm{Co}=10: 90$, j) $\mathrm{Fe}: \mathrm{Co}=01: 99$

Figure 1. Mössbauer spectra of different $\mathrm{Fe}-\mathrm{Co}$ ratios. 

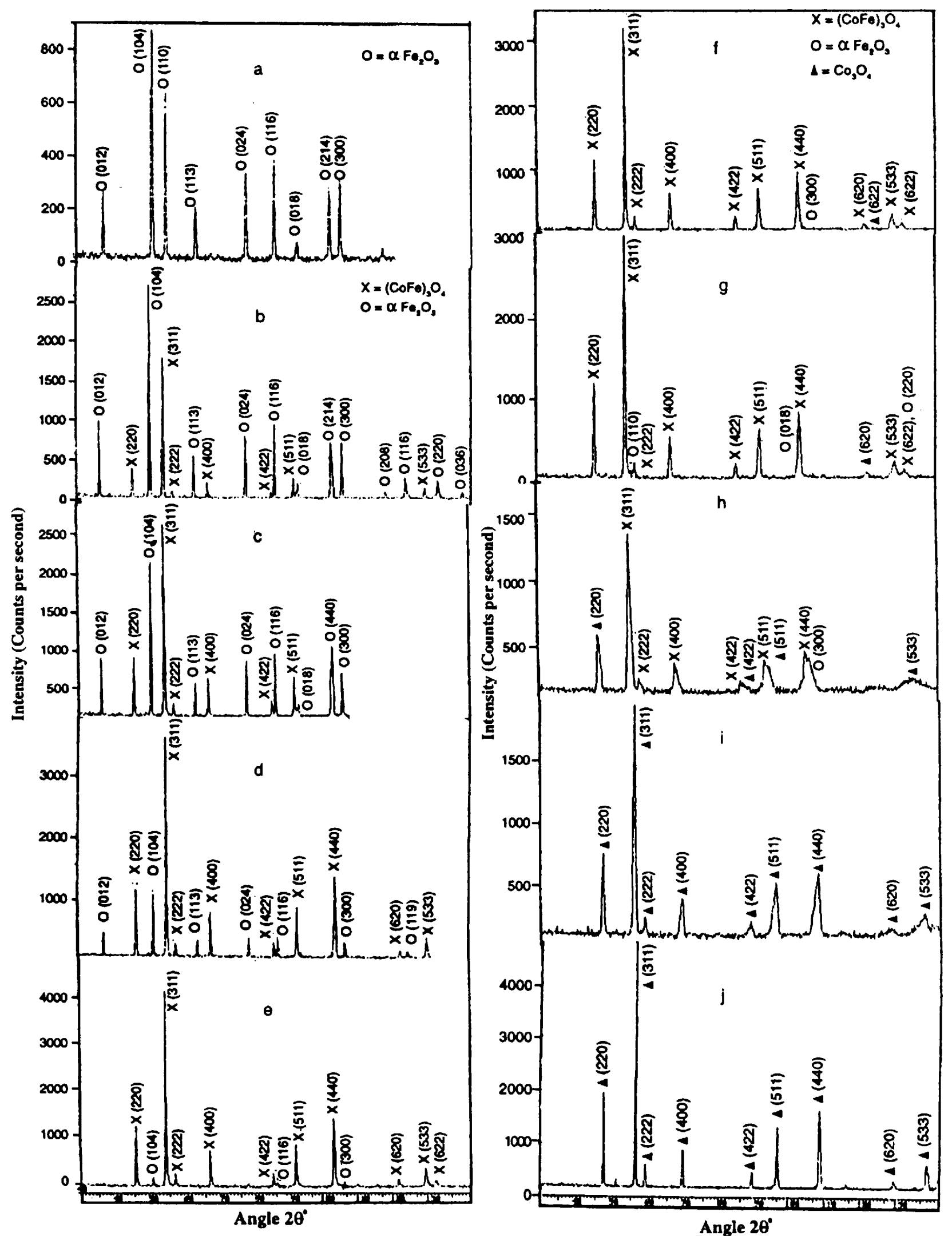

a) $\mathrm{Fe}: \mathrm{Co}=100: 0$, b) $\mathrm{Fe}: \mathrm{Co}=90: 10$, c) $\mathrm{Fe}: \mathrm{Co}=80: 20$, d) $\mathrm{Fe}: \mathrm{Co}=70: 30$, e) $\mathrm{Fe}: \mathrm{Co}=60: 40$, f) $\mathrm{Fe}: \mathrm{Co}=50: 50$, g) $\mathrm{Fe}: \mathrm{Co}=40: 60$, h) $\mathrm{Fe}: \mathrm{Co}=25: 75$, i) $\mathrm{Fe}: \mathrm{Co}=10: 90$, j) $\mathrm{Fe}: \mathrm{Co}=0: 100$

Figure 2. X-ray diffractograms of different $\mathrm{Fe}-\mathrm{Co}$ ratios. 
all these samples which gave ferrite phase. The crystallite size and unit cell volume of these ferrite samples have their maximum values of $548 \AA$ and $477 \cdot 8 \AA^{3}$, respectively at this particular sample ratio $\mathrm{Fe}: \mathrm{Co}=60: 40$. This also implies that the ferrite formation is maximum at this ratio.

Table 5 is prepared using XRD patterns to study the variation of intensity of first three intense peaks with $h \mathrm{kl}$ values $311,440,220$, respectively with increase of cobalt concentration in the sample. This intensity variation is graphically represented in figures 3-5. These three graphs clearly indicate that the intensity of each peak attains the maximum value only at the particular sample ratio given by $\mathrm{Fe}: \mathrm{Co}=60: 40$.

The intensity variation study on Mössbauer spectra of these ferrite samples are shown in table 6. Here the intensity variation of the spectra due to $A$ and $B$ sub lattice

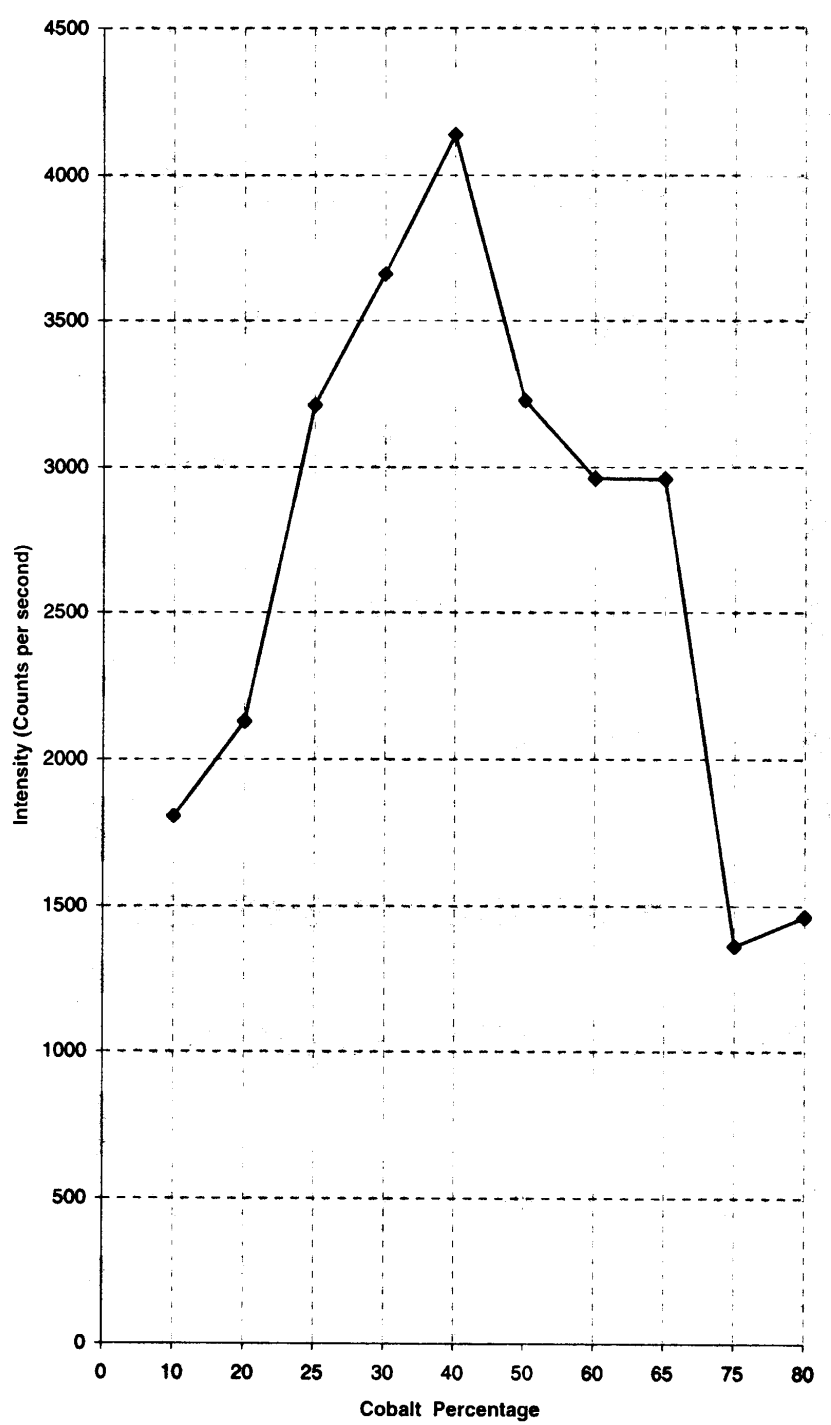

Figure 3. Intensity variation of 1 st intense peak $(h k l=311)$ of ferrite phase with cobalt concentration in XRD. sites of ferrite phase are separately found with the cobalt concentration. This intensity variations are graphically represented in figure 6 and it implies that the intensity of ferrite phase attains its maximum value at a cobalt concentration of $40 \%$ (circled region), i.e. $\mathrm{Fe}: \mathrm{Co}=60: 40$ for both $\mathrm{A}$ and $\mathrm{B}$ sites. This undoubtedly indicates the suitability of the sample ratio $\mathrm{Fe}: \mathrm{Co}=60: 40$ for the ferrite formation.

\section{Conclusions}

With this particular method of preparation we have been able to produce nano-size cobalt ferrite particles (with defect structure) in powder form. By eliminating sintering we could reduce the duration of preparation also. The growth and decay of the cobalt ferrite particles of inverse spinel type with variation of the $\mathrm{Fe}$ : Co ratio are clearly



Figure 4. Intensity variation of 2 nd intense peak $(h k l=440)$ of ferrite phase with cobalt concentration in XRD. 


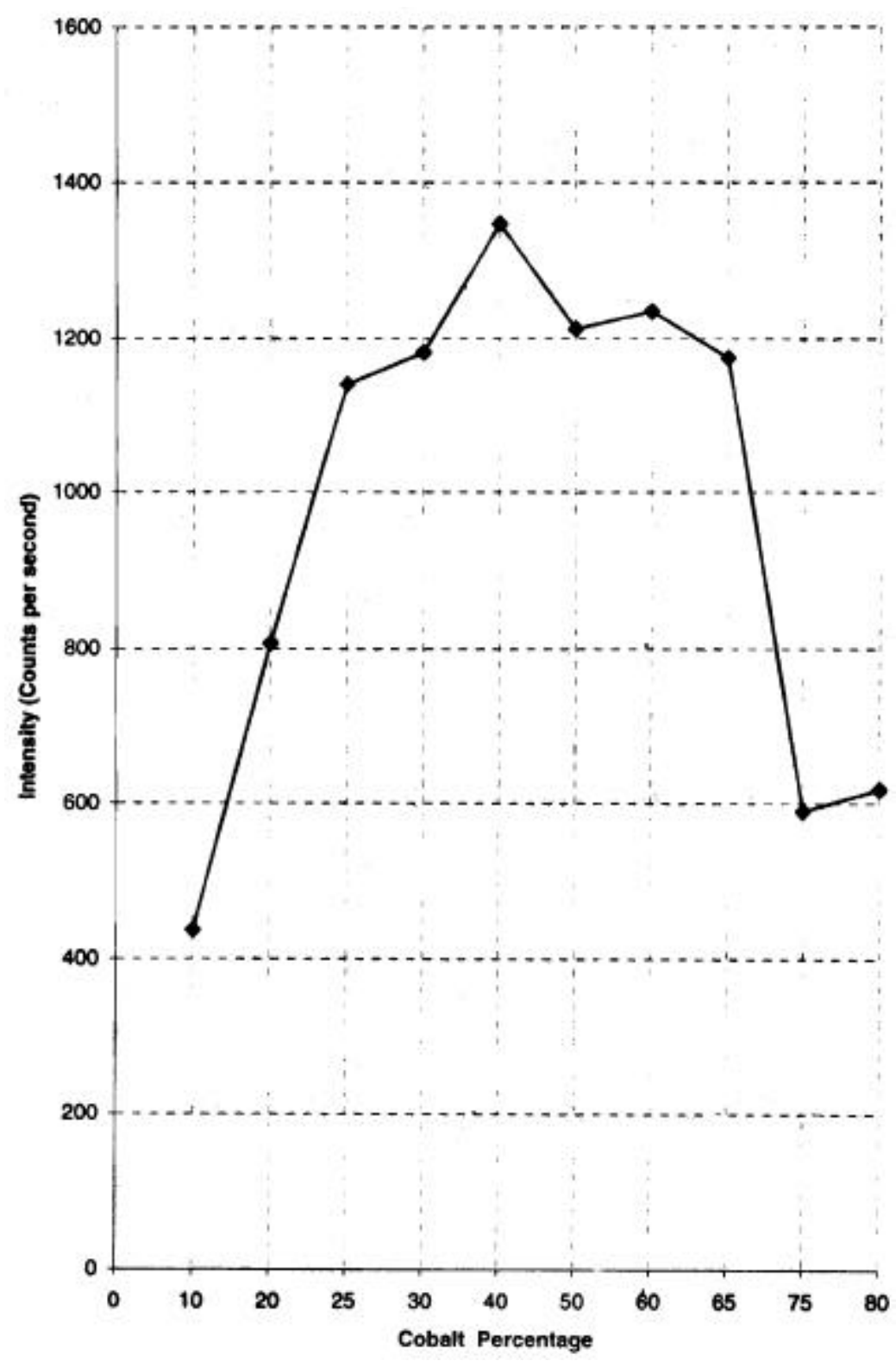

Figure 5. Intensity variation of 3rd intense peak $(h k l=220)$ of ferrite phase with cobalt concentration in XRD.

Table 5. Intensity variation of $(\mathrm{CoFe})_{3} \mathrm{O}_{4}$ phase in $\mathrm{XRD}$ with cobalt concentration.

\begin{tabular}{lccc}
\hline $\begin{array}{l}\text { Sample } \\
\text { ratio }\end{array}$ & $\begin{array}{c}\text { 1st intense peak } \\
h k l(311)(\mathrm{cps})\end{array}$ & $\begin{array}{c}\text { 2nd intense peak } \\
h k l(440)(\mathrm{cps})\end{array}$ & $\begin{array}{c}\text { 3rd intense peak } \\
h k l(220)(\mathrm{cps})\end{array}$ \\
\hline $90: 10$ & 1807 & 628 & 437 \\
$80: 20$ & 2127 & 945 & 807 \\
$75: 25$ & 3212 & 970 & 1140 \\
$70: 30$ & 3662 & 1410 & 1182 \\
$60: 40$ & 4138 & 1465 & 1347 \\
$50: 50$ & 3228 & 1030 & 1212 \\
$40: 60$ & 2962 & 892 & 1235 \\
$35: 65$ & 2960 & 842 & 1175 \\
$25: 75$ & 1362 & 212 & 618 \\
$20: 80$ & 1463 & 215 & 618 \\
\hline
\end{tabular}


Table 6. Intensity variation of $(\mathrm{CoFe})_{3} \mathrm{O}_{4}$ phase with cobalt concentration in Mössbauer spectra.

\begin{tabular}{lcc}
\hline & \multicolumn{2}{c}{ Intensity of $(\mathrm{CoFe})_{3} \mathrm{O}_{4}$ phase $(\%)$} \\
\cline { 2 - 3 } Sample ratio & A-site & B-site \\
\hline $80: 20$ & $50 \cdot 5$ & $24 \cdot 5$ \\
$75: 25$ & $33 \cdot 27$ & $16 \cdot 67$ \\
$70: 30$ & $20 \cdot 5$ & $9 \cdot 53$ \\
$60: 40$ & $23 \cdot 23$ & $25 \cdot 87$ \\
$50: 50$ & $11 \cdot 52$ & 12.43 \\
$40: 60$ & $11 \cdot 8$ & $8 \cdot 04$ \\
$35: 65$ & $7 \cdot 82$ & $7 \cdot 26$ \\
$25: 75$ & $2 \cdot 824$ & 247 \\
$20: 80$ & $2 \cdot 58$ & 1.595 \\
\hline
\end{tabular}

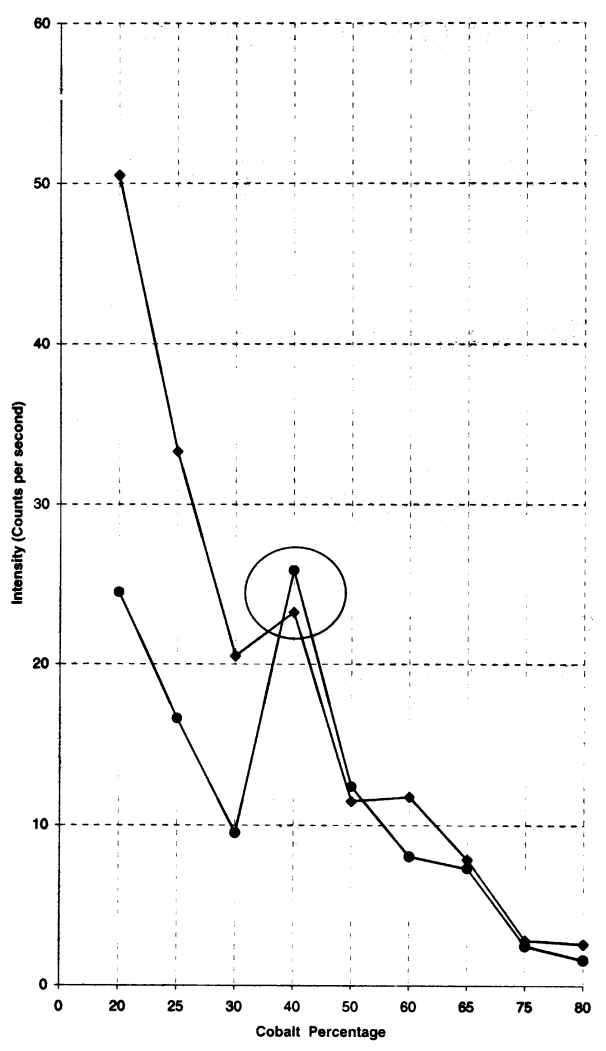

Figure 6. Intensity variation in Mössbauer spectra due to A \& B sites of spinel ferrite phase with cobalt concentration.

understood from the variations in the Mössbauer and XRD patterns. The cobalt ferrite formation is found to be maximum at the sample ratio $\mathrm{Fe}: \mathrm{Co}=60: 40$ from both
Mössbauer and XRD analysis and this ratio can be considered as the most suitable one for the cobalt ferrite preparation by this method.

\section{Acknowledgements}

The authors wish to thank Prof. M N Anandaram, Chairman, Department of Physics, Bangalore University, for his cooperation to carry out this work. The authors are grateful to Prof. N G Puttaswamy, Emeritus Professor, Bangalore University, Bangalore and Prof. R M Mallya, Indian Institute of Science, Bangalore, for their encouragement and help. One of the authors (MDJS) thanks research students Mr Raghavendra and Mr K V Thipperudraiah for their help. He also sincerely thanks the University Grants Commission, New Delhi, for the award of a teacher fellowship under FIP.

\section{References}

Abdeen A M, Hemeda O M, Assem E E and El-Sehly M M 2002 J. Magn. Magn. Mater. 23875

Drakshayani D N 1987 Reactivity of solids: Reduction of some transition metal oxides of marine manganese nodules by hydrogen, M.Sc. Thesis, Indian Institute of Science, Bangalore

Drakshayani D N 1994 Reactivity of solids: Effect of dopants on low temperature hydrogen reduction on ferrite oxides and metastable spinels, Ph.D. Thesis, Indian Institute of Science, Bangalore

Kwang Pyo Chae, Young Bae Lee, Jae Gwang Lee and Sung Ho Lee 2000 J. Magn. Magn. Mater. 22059

Martha Pardavi-Horvath 2000 J. Magn. Magn. Mater. 215 171

Rajendran 2001 J. Magn. Magn. Mater. 23875

Randhawa B S 2000 J. Mater. Chem. 102847

Souad Ammar, Arnaud Helfel, Noureddin Jouini, Fernand Fievet, Izio Rosenman, Francoise Villain, Philippe Molinie and Michel Danot 2001 J. Mater. Chem. 11186

Thipperudraiah K V 2001 Mössbauer effect and X-ray diffraction studies of thermal decomposition of homogeneously mixed iron-cobalt oxides in hydrogen, Ph.D. Thesis, Bangalore University, Bangalore

Vanderberghe R E, Vanleerberghe R, De-Grave E and Robrecht G 1980 J. Magn. Magn. Mater. 151117

Warren B Cross, Lousie Affleck, Maxim V Kuznetsov, Ivan P Parkin and Quentin A Pankhurst 1999 J. Mater. Chem. 9 2545 